\title{
Features of Implementation of Precision Agriculture Technologies on Cultivated Slope Lands
}

\author{
Sergey Anatolyevich Vasilyev \\ Department of applied mechanics and graphics \\ Chuvash state university named after I.N. Ulyanov \\ Cheboksary, Russia \\ vsa_21@mail.ru
}

\begin{abstract}
The article discusses the specific features of implementation of precision farming technologies on cultivated slope lands. Cultivated slope land is a natural-territorial complex, the natural vegetation of which is mostly replaced by agrocenoses. Because of their ecological instability, the complex of agronomic, melioration and ecological measures is carried out to ensure the stability of this sort of soil.

When estimating the condition of the cultivated slope lands, it is necessary to take into account the parameters of the slopes, the size of the contours, hydrological regime, types and varieties of soils, erosion processes, economic conditions, location, etc. The monitoring of these parameters will make it possible to detect timely hidden impacts or changes, and to recover the stability of the agroecosystem as in case of maintaining the hydrodynamic characteristics of the soil cover for a certain period of time.

In order to detect the hydrodynamic characteristics of soil and vegetation cover, some measurement data are necessary to estimate the water balance components of the cultivated slope lands, a number of measurement data of soil and vegetation cover and data of Earth's remote sensing (ERS).

For remote monitoring of agricultural lands, we use multispectral satellite images made by means of Earth's remote sensing offered by the European space Agency that allows one to establish Normalized Difference Vegetation Index NDVI and land configuration.

The RTK-mode ensures the operation of the autopilot system and course indicator with the accuracy of $5 \mathrm{~cm}$.

The system receives, processes and stores data of the remote diagnostics of agricultural machinery, weather forecast and other data for 5-10 days. Ground-based technical means of control of the underlying surface were used for ground monitoring. Field research procedures have been performed using different soil fertility with the use of the laser profile recorder of non-contact and contact type. As a result of experimental studies, the specific features of precision farming technologies implementation were established and the prospects of their application on slope lands were determined.
\end{abstract}

Keywords - precision agriculture, Earth's remote sensing, monitoring of agricultural machinery

\section{INTRODUCTION}

Cultivated slope lands represent a natural and territorial complex, the natural vegetation of which is mostly replaced by agrocenosis [3]. Since it is characterized by ecological instability, a system of agronomic, meliorative and ecological measures is carried out to ensure its stablility. [2]. The ability of the ecosystem to return to the original stablily after temporary influence of a natural or anthropogenic factor characterizes its stability. Estimating the state of cultivated slope lands, it is necessary to consider the parameters of the slopes, the sizes of contours, the hydrological mode, types and kinds of soils, erosive processes, economic conditions, location, etc. $[4,8]$.

It is apparent that along with the parameters responsible for stability of the agroecosystem, the productivity plays the main role. Its decrease to a certain value, for example, owing to soil erosion, overwetting, drought or soil degradation, determines the transition of the ecosystem to an unstable state. At the same time crop productivity decrease will be a critical state of the agroecosystem due to the impact of natural and anthropogenic disturbances.

We can avoid this state by monitoring a number of hydrophysical and erosive parameters of the agrolandscape catena in dynamics, including the level of soil fertility.

Monotoring the above parameters will give an opportunity to reveal hidden impacts or changes, and in due time restore the agroecosystem stability, for example, to maintain the hydrodynamic characteristics of the soil cover during a certain period.

Thus, it is not reasonable to consider the stability of an agroecosystem on the basis of one or two disturbing factors as in some mathematical models. Complex research on cultivated land catena applying methods of mathematical modeling and analysis is most effective.

Determining the zones and areas on the catena, which are subject to significant negative impacts and as well as their boundaries and sizes in time and in space, represents some difficulties. These problems have not been fully investigated even in the form of some concepts.

The research and designing of cultivated land catenas on the basis of the analysis of the hydrodynamic characteristics of the soil and vegetation cover of slope lands are one of the fundamental scientific tasks in the field of the problem being studied.

In order to determine hydrodynamic characteristics of the soil and vegetation cover, we need measurement data to estimate water balance components of cultivated slope lands, 
data of soil and vegetation cover parameters, as well as the data of the Land Remote Sensing (LRS).

It is known that the value of the components of the developed modified equation of a water flow motion is determined by experimentally measured hydrophysical and erosion parameters of the studied cultivated land catena $[1,3]$ as well as their dynamics in time and space.

\section{MATERIALS AND METHODS}

The existing methods of forecasting quite often require very long and laborious experimental observations of the processes of agrocenosis and biogeocenosis under specific conditions and in most cases cannot be used in other soil- climatic and geomorphological conditions [1].

Some other approaches require experimental determining of critical values of hydrophysical parameters for the entire morphostructure of soil cover, or applying hypotheses simplifying the process, which do not always satisfy the process being studied or lead to serious errors [7].

Therefore, to study the problem of spatial and time changes in the parameters of hydrophysical parameters, space and ground monitoring approaches are used $[5,6]$.

Satellite monitoring is carried out by aerospace methods of obtaining information, for example, for remote monitoring of agricultural lands we use multispectral satellite images received from the European Space Agency's remote sensing satellites, allowing one to establish the Normalized Difference

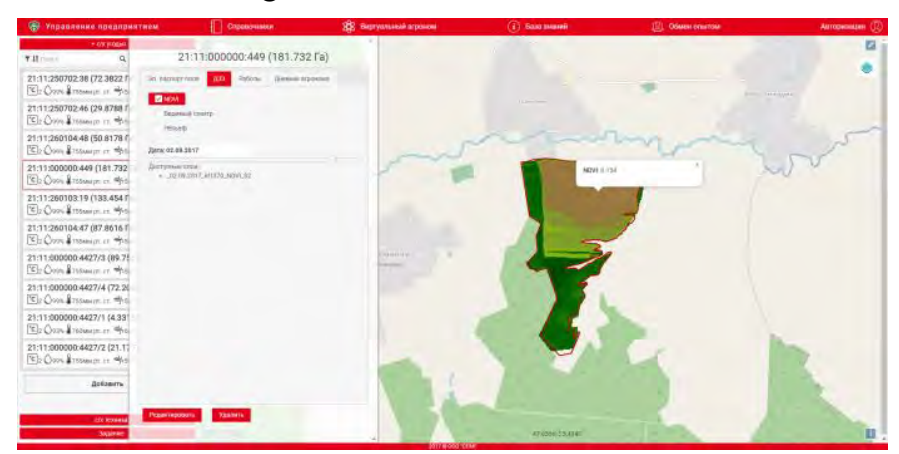

Fig. 1. Fragment of the map presenting the data on the Normalized Difference Vegetation Index, NDVI in the system

The system also uses radar satellite images of remote sensing satellites of the European Space Agency "Sentinel-1". The interval of taking pictures is 3 days; the spatial resolution is $5 \mathrm{~m} /$ pixel (without processing).

The map of land configuration is made by means of radar images. Above sea level, the altitude in the area is calculated in meters.

To monitor the movement of agricultural machinery and and to detect agricultural operations, the common GPS / GLONASS terminal is installed on the machinery. It transmits machinery location coordinates to the server as well as its speed and above sea level altitude calculated from the signals received from navigation satellites by calculating the coordinates.
Vegetation Index, NDVI and land configuration. The RTKmode ensures the operation of the autopilot system and course indicator with the accuracy of $5 \mathrm{~cm}$.

The remote cloud system receives, processes and stores the following data on remote diagnostics of agricultural machinery, weather forecast data for 5-10 days and others.

For remote monitoring of agricultural lands, multispectral satellite images made by the Earth remote sensing satellites of the European Space Agency "Sentinel-2" were used. The interval was 10 days, the spatial resolution $-10 \mathrm{~m} /$ peak, 13 spectral channels ranging from the visible and near infrared to the shortwave infrared range of spectrum.

Currently, the system makes the calculation of the map of the Normalized Difference Vegetation Index NDVI using spectral channels in the red (0.55-0.75 microns) and nearinfrared spectrum (0.75-1.0 microns ) for the calculation. It is calculated according to a well-known formula:

$$
\mathrm{NDVI}=(\mathrm{NIR}-\mathrm{Red}) /(\mathrm{NIR}+\mathrm{Red}),
$$

where NIR is the reflection in a near infrared area,

Red - the reflection in the red range of spectrum.

Data on the relative Normalized Difference Vegetation Index (NDVI) on the map fragment are shown in fig. 1.

The NDVI calculations for the area being tested with an area of 181.73 hectares were made on September 2, 2017, for example, at the specified point of the area (see Figure 1), the NDVI value is 0.154 .

The distance triangulation to visible satellites with known coordinates is travelled, and the distance is calculated by a signal delay time when passing from the satellite to the object. To operate the autopilot system and course indicator with an accuracy of $5 \mathrm{~cm}$, the RTK mode is used

In the RTK mode, the geomonitoring base station, which is the source of differential positioning corrections, sends the geopositioning corrections to the server via the GSM channel. Then the device calculates geopositions using the corrections received from the server.

Thus, the base station, detectimg its geoposition, determines the positioning error calculated by the signals of navigation satellites which coordinates are known.

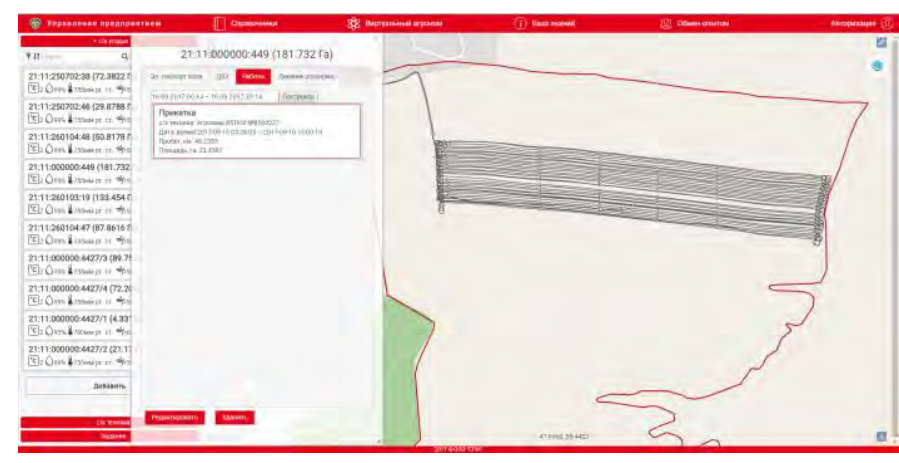

Fig. 2. The trajectory of agricultural operation in the system 
The trajectory of performing the agricultural operations by machinery in the system is shown in Fig. 2. It was established that a machine-tractor unit cultivated the area of 23.46 hectares from 5:26 till 13:00 p.m, 16.09.2017, and the tractor Agromash 85TK ran $46.24 \mathrm{~km}$.

Wireless soil condition sensors and integration of the API system with the OpenWeatherMap meteorological service allows one to monitor the current state of the soil and the environment, to forecast the weather for the next 5-10 days.

Ground technical control facilities were used for soil cover control [3].

Field research was conducted on different agricultural backgrounds (plowing, plowing with a harrowing, mulching, autumn sowing, disk plowing, grain stubble, etc.) using noncontact and contact laser profilographs (fig. 3) [3].

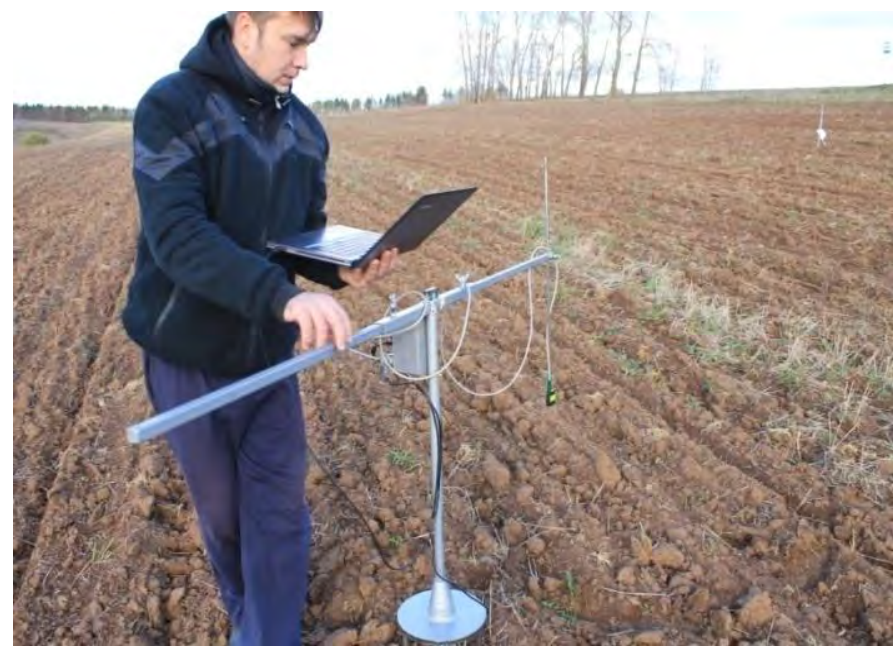

Fig. 3. Field research by means of non-contact profilograph in the field after disk plowing

\section{RESULTS AND DISCUSSION}

We studied cultivated slope lands on the territories of agricultural complex "Trud" in Batyrevsky district, interfarm irrigation system "Druzhba" in Kanashsky district and SPK "Orinino" in Morgaushsky district of the Chuvash Republic [3].

The results of the research in the field located on a nonuniform slope after minimum cultivation by disk harrow BDM-3x4P (heavy disk modernized hook-on harrow), monitored on the screen in polar coordinates, are shown in Fig. 4.

As a result of pilot operation, the following features of the implementation of digital farming technology were established:

- the earth remote sensing by means of multispectral satellite images strongly depends on the air condition and are in general suitable for use once a month;

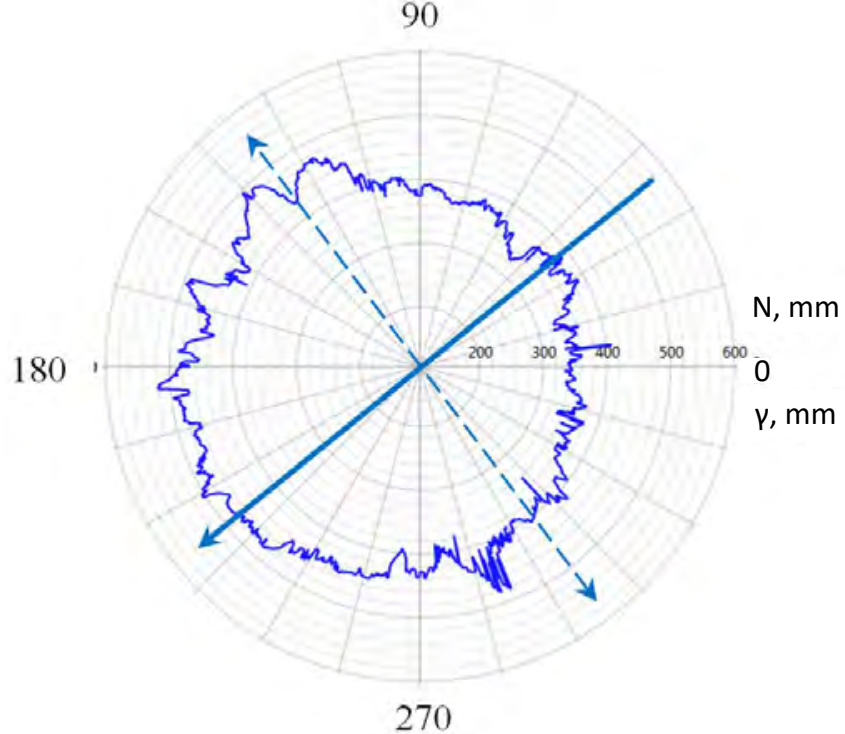

$\leftarrow \quad$ - direction of the slope

Fig. 4. Results of field research in polar coordinates by means of the profilograph for the field area after disk plowing

- radar satellite images are more acceptable for fixing the dynamics of changing parameters, since they are not affected by cloudiness, but they are less informative than multispectral satellite images;

- accuracy of positioning without using the RTK mode reaches up to 5 meters and is highly dependent on the air condition and the presence of a reflected signal from buildings and the forest;

- the installed sensors of the soil and the environment can increase the accuracy of calculating the weather forecast considerably;

- the use of profilographs allows one to determine the direction and the size of the slope of the soil surface, waviness and roughness of the soil surface of the tested area, the deviation angle of the direction of cultivation from the direction of the slope in field environment.

The revealed features of the implementation of digital farming technology determine the prospects for the use of software and ground-based scanning tools in the agroindustrial complex.

To expand the capabilities of remote monitoring of agricultural lands, it is necessary to create:

- snow cover maps;

- maps of nitrogen content in plant leaves;

- maps of chlorophyll content in plant leaves;

- maps of moisture content in soil and plant leaves. 
To implement digital farming on cultivated slope lands, it is necessary to use the following items, referring to the following articles $[2,5,6]$ :

- maps of slope exposition;

- maps of slope angle;

- map of linear erosion thickness index;

- the map of topographic conditions for the development of landscape surface flood - LSF index;

- soil cover hydromorphic maps - the topographic humidity index.

\section{CONCLUSION}

The revealed features of the implementation of digital farming technology determine the prospects for the use of software and ground-based scanning tools in the agroindustrial complex, which will increase the accuracy of agrotechnical estimation of the field surface after cultivating with the machines performing various agricultural operations.

In general, the introduction and implementation of digital farming technology will allow agricultural enterprises to improve crop yields up to $50 \%$, reduce production costs and increase their profits.

\section{Acknowledgment}

The research was carried out within the RFBR grant № 18416-210001 p_a

\section{References}

[1] Y.V. Bondarenko "Geoinformation support of the design of adaptive landscape melioration of water-shed areas system" Scientific life, vol. 2, pp. 58-64, 2016.

[2] S.A. Vasilyev, I.I. Maksimov, V. I. Maksimov, Hydraulic roughness of cultivated slope lands, Cheboksary, Modern time, 2014, p. 210

[3] S. A. Vasilyev, "Development of methods and technical control facilities for erosion-preventing technologies applied on cultivated slope lands" Moscow, 2017, p. 345

[4] S. A. Vasilyev "Features of application of erosion-preventing meliorative actions appied on various cultivated slope lands" Environmental engineering, vol. 4, pp. 86-92, 2016.

[5] S. A. Vasilyev, I. I. Maksimov, E. P. Alekseev "The results of pilot studies of hydrophysical and erosive properties of soils in the territory of SHPK Trud of Batyrevsky district of the Chuvash Republic," Bulletin of the Chuvash state pedagogical university named after I.Y. Yakovlev, vol. 4-2, pp. 39-45, 2013.

[6] A. N. Dmitriev, S. A. Vasilyev, V. V. Alekseev "The results of soil and meliorative research in reconstructing of the interfarm irrigating "Druzhba" system of the Chuvash Republic," Melioration and water management, vol. 2, pp. 17-21, 2016.

[7] N.I. Dobrotvorskaya "The information support of the design of adaptive and landscape agriculture systems" News of the Orenburg State Agricultural University, vol. 57, pp. 151-154, 2016.

[8] I. I. Maksimov, V. I. Maksimov, S. A. Vasilyev "Simulating the course deformation of the cultivated slope lands soil cover" Soil science, vol. 4, pp. 514-519, 2016. 